\title{
Control of Delta-Wing Vortex by Apex Strake
}

\author{
Myong Hwan Sohn* and Hyoung Seog Chung* \\ Department of Aerospace Engineering \\ Korea Air Force Academy \\ Cheongwon-Gun, ChungBuk-Do, Korea 363-849
}

\begin{abstract}
The vortex flow characteristics of a double-delta wing, which can change the incidence angle of its apex strake was investigated through the wing-surface pressure measurement and the particle image velocimetry(PIV) measurement of the wing-leeward flow region. The apex strake has sharp edges and can change its incidence angle with a hinge line at the $23 \%$ chord position measured from the apex of the main wing. The present study revealed that the incidence-angle change of the apex strake could greatly alter the vortex flow pattern around the double-delta wing and the wing-surface pressure distribution, which suggested that the apex strake could be used as an effective device for the active control of delta-wing vortex flow.
\end{abstract}

Key Word : delta-wing vortex, apex strake, flow control, PIV measurement, wing surface pressure

\section{Introduction}

Vortex flows over delta wings contribute a large amount of aerodynamic force generation; therefore, many studies have been carried out to search for the ways of controlling vortex flows to enhance the stability and controllability characteristics of delta wings, or even further to replace the conventional control surfaces. With the help of the recent development of micro-electro-mechanical-systems(MEMS) techniques and synthetic jet systems, the research efforts in this field has been accelerated and various new methods of controlling vortex structures around a delta wing have been tested. The techniques investigated in the previous researches can be mainly divided into two categories: a) direct flow-momentum control utilizing blowing jets located at apex, leading edge or trailing edge of delta wings, b) shape or configuration modification of delta wing itself. The literatures for the latter category include a sweepback-angle variation method[1], apex-flap methods[2, 3, 4], leading-edge vortex-flap method[5, 6, 7, 8], and trailing-edge vortex-flap methods[9]. The results of the previous research[10] indicated that the shape modification was a more effective method for altering vortex flow than the direct flow momentum control method using jets since vortex flows generated from delta wings maintained fairly strong and stable structure up to a certain degree of angle of attack.

In the present study, the vortex flow characteristics of a double-delta wing with changable apex strake was investigated through the wing-surface pressure measurement and the particle image velocimetry(PIV) measurement of the wing-leeward flow region. The apex strake has sharp edges and can change its incidence angle with a hinge line at the $23 \%$ chord position measured from the apex of the main wing. The flow Reynolds number was $8.2 \times 10^{5}$ based on the free stream velocity of $20 \mathrm{~m} / \mathrm{sec}$ and the root chord of the experimental model $(600 \mathrm{~mm})$.

* Professor

E-mail : myongsohn@hanmail.net

Tel : 043-290-6461

Fax : 043-298-6160 
Klute et al.[3] examined the effects of a drooping apex flap for fixed and pitching delta wings of $75^{\circ}$-sweep angle. They suggested that an apex flap could delay vortex breakdown by an angle of $8^{\circ}$ beyond the steady-flow breakdown angle of attack. Zhan and Wang[4] studied the effects of Gurney flaps and apex flaps on the longitudinal aerodynamic performance of a delta wing with $70^{\circ}$-sweep angle through force and moment measurements. They suggested that the simultaneous use of apex flap and Gurney flap could greatly improve the longitudinal aerodynamic performance, and the apex flap contributed much to the gains. Sohn et al.[14] investigated the vortical flow of a $65^{\circ}$-sweep sharp-edged delta wing with the cropped-delta shape strake of $65^{\circ} / 90^{\circ}$-sweep. Their results confirmed the stabilizing effect of strake. The vortex system of the double-delta wing with strake was stronger, more stabilized, and more breakdown-resistant to sideslip. The experimental model of the present study is a $65^{\circ}$-sweep round-edged delta wing. Therefore, the double-delta wing with the apex strake shape of the present study is different from Klute et al.'s model $\left(75^{\circ}\right.$-swep single-delta wing), Zhan and Wang's model $\left(70^{\circ}\right.$-sweep single-delta wing), and Sohn et al.'s model $\left(65^{\circ}\right.$-sweep sharp-edged delta wing).

\section{Experimental Set-up and Procedures}

\section{Wind Tunnel}

The experimental apparatus was set up at the Korea Air Force Academy Low-Speed Wind Tunnel. The medium-scale test facility is a closed-circuit atmospheric tunnel having a test section of $3.5 \mathrm{~m}(\mathrm{~W}) \times 2.45 \mathrm{~m}(\mathrm{H}) \times 8.7 \mathrm{~m}(\mathrm{~L})$ with a maximum free stream velocity of $92 \mathrm{~m} / \mathrm{sec}$. The contraction ratio is $7.26: 1$, flow angularity is less than $0.1^{\circ}$, and the axial turbulence intensity ( $u^{\prime} / \mathrm{U}$ ) is $0.04 \%$ at the free stream velocity of $74 \mathrm{~m} / \mathrm{sec}$.

\section{Experimental Model}

The experimental model was a flat-plate $65^{\circ}$-sweep delta wing with round leading edges of semi-circular section, and had the root chord of $600 \mathrm{~mm}$, the trailing edge span of $500 \mathrm{~mm}$, and the thickness of $15 \mathrm{~mm}$. The strake was also a flat wing with a planform of the $65^{\circ} / 90^{\circ}$-sweep cropped-delta shape, and had the root chord of $273 \mathrm{~mm}$ and the thickness of $6.35 \mathrm{~mm}$. The leading and side edges of the strake were symmetrically beveled. The apex portion of the delta wing can be removed and replaced with the strake to form a double-delta wing configuration with the root chord of $735 \mathrm{~mm}$. The lower wing surface was mounted with a fuselage-like structure that served as the housing for the pressure tubes and model support. Fig. 1 shows the model geometry of the integrated configuration and the definitions of the incidence angle of the apex strake $(\delta)$.

The main wing was equipped with three spanwise rows of upper-surface static pressure taps for pressure measurements. The pressure rows were located at the $30 \%, 50 \%$, and $70 \%$ wing chord(c) stations, measured from the main wing apex. There were 23-35 pressure taps on each chord station along the entire span. The spanwise locations of the pressure taps ranged from $\mathrm{y} / \mathrm{s}=0.0$ to $\mathrm{y} / \mathrm{s}=0.75$ (30\% chord station), $\mathrm{y} / \mathrm{s}=0.85$ (50\% chord station), and $\mathrm{y} / \mathrm{s}=0.95(70 \%$ chord station), s being the local semi-span.

\section{Wing-Surface Pressure Measurement}

Static pressure on the wing upper surface was measured by a PSI 9400 pressure measurement system. The measurement rate was $0.2 \mathrm{sec} /$ measure. The wing surface pressure data in this study was an ensemble average of 300 pressure signals from each pressure tap. The free stream velocity was $20 \mathrm{~m} / \mathrm{s}$, which corresponded to the Reynolds number of $8.2 \times 10^{5}$. The uncertainty analysis for pressure measurements was carried out in order to assess the data accuracy and confidence level, following the method suggested in AIAA Standard[11]. It was estimated that the pressure measurement uncertainty for the present study was less than $\pm 24.86 \mathrm{~Pa}$ at $95 \%$ confidence level, which was about $0.36 \% \mathrm{~F}$.S. 


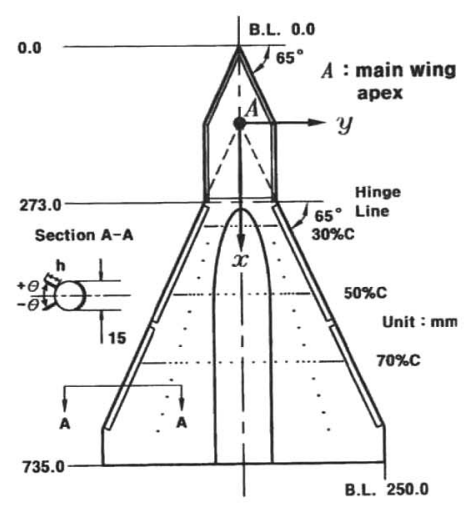

(a) geometry of model

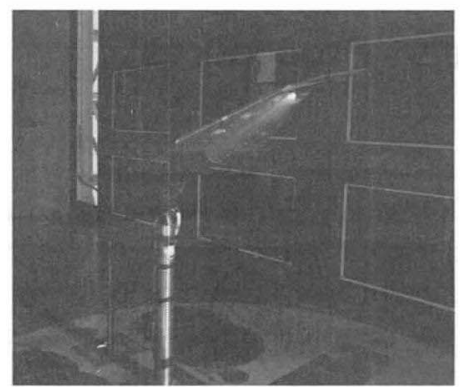

(c) model in wind tunnel

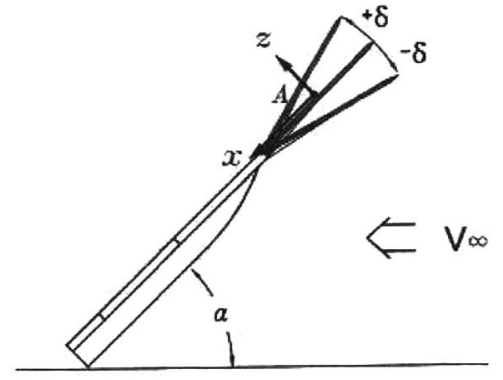

(b) strake incidence-angle

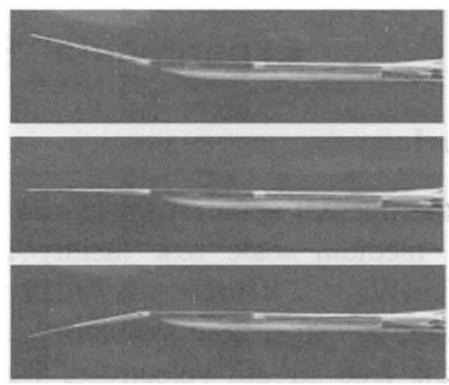

(d) strakes at $\delta=+15^{\circ}, 0^{\circ}$ and $-15^{\circ}$

Fig. 1. Experimental model

\section{PIV Measurement}

The PIV System used in this study consists of a double-pulse Nd:YAG laser(Vlite-200) with a maximum pulse energy of $2200 \mathrm{~mJ}$ at a repetition rate of $10 \mathrm{~Hz}$, a 8-bit digital CCD with a resolution of $2048 \times 2048$ pixels, and a PC equipped with DaVis FlowMaster software and a synchronization board developed by LaVision GmbH for the system synchronization, control, data acquisition and post-processing. An aerosol Generator was used for $\operatorname{DEHS}\left(\mathrm{C}_{26} \mathrm{H}_{50} \mathrm{O}_{4}\right)$ particle seeding. The tunnel was filled with particles beforehand and the generator was turned off during the actual measurements. The PIV data in this study was an ensemble average of 20 instantaneous velocity fields. The estimation of the uncertainty of PIV velocity measurements requires many factors to be examined, such as the uncertainty in the determination of the geometrical parameters and the fabrication tolerances of the camera device, lenses and laser system, as well as the uncertainty in the determination of the average particle displacement in the interrogation region[12]. The total uncertainty consists of bias error and precision error. The estimation of bias error requires the information about the sensitivity of the various factors affecting the measurements, which, in turn, requires an extensive experimental test in a carefully prepared environment. However, the bias error can be minimized with the careful calibration of measuring instruments[13]. The precision error was estimated by calculating the standard deviation of 30 sample records with the coverage factor of 2 at $95 \%$ confidence level. The estimated uncertainties of the PIV velocity components in the region near the strake vortex were 12.5 and $13.3 \%$ for $\mathrm{v}$ and $\mathrm{w}$ velocity components, respectively, based on the maximum velocity components measured. The uncertainties appear large because the vortex formation meanders causing the instability of the vortex location. However, in regions where the flow behaves well (away from the vortex systems), the uncertainties for each velocity components decreased less than $2.2 \%$. 


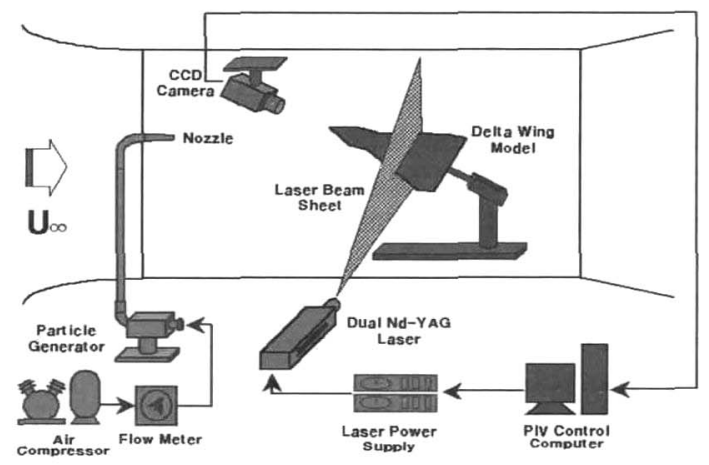

Fig. 2. PIV measurement system

\section{Results and Discussion}

Fig. 3 shows the cross-flow velocity field and the streamwise vorticity field for the strake incidence angle of $0^{\circ}$ at an angle of attack of $24^{\circ}$. The streamwise vorticity was obtained by differentiating the cross-flow velocity vector measured by PIV. The blue-colored region represents the vortex system rotating in clockwise direction, and the red-colored region represents the vortex system rotating in counterclockwise direction. The vortices generated by the sharp-edged strake(strake vortices) located in inboard flow region above the wing surface at the $30 \%$ chord station as shown in Fig. 3a. At the $50 \%$ chord station, the wing vortices are located outboard and adjacent to the wing surface as shown in Fig. $3 \mathrm{~b}$. The size and strength of the strake and wing vortices were comparable with each other at this mid-chord station. Two distinct vortex pairs of strake and wing vortices coiled and merged into one big vortex system as they traveled downstream. This process can be observed in Fig. 3c, in which the strake vortex moved downward and ourboard direction while the wing vortex moved upward and inboard direction. The distance between the core locations of two vortices became shorter indicating the merging process. The strength of the strake vortex was getting weaker as going downstream whereas that of the wing vortex remained almost constant level. This phenomenon is due to the fact that the wing vortex was continuously energized from the leading edge section of the delta wing. Meanwhile, the strake vortex was only energized at the strake portion of the wing, thus its strength quickly diminished at the downstream region.

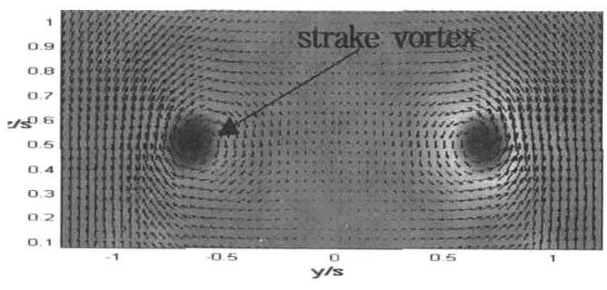

(a) $x / c=0.30$
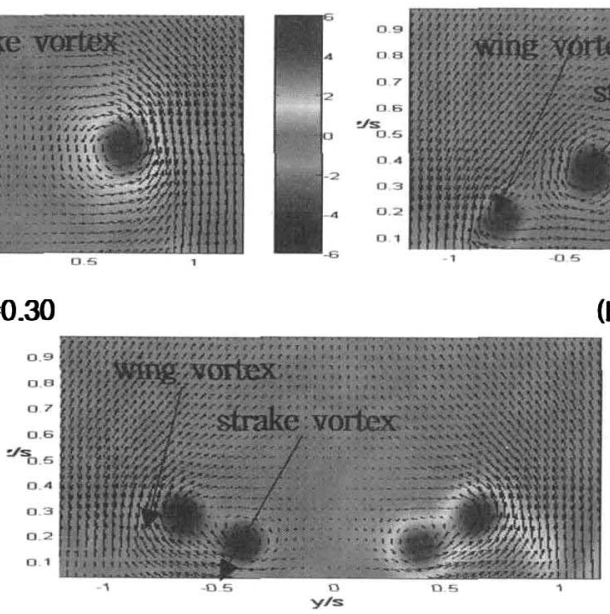

(c) $x / c=0.70$

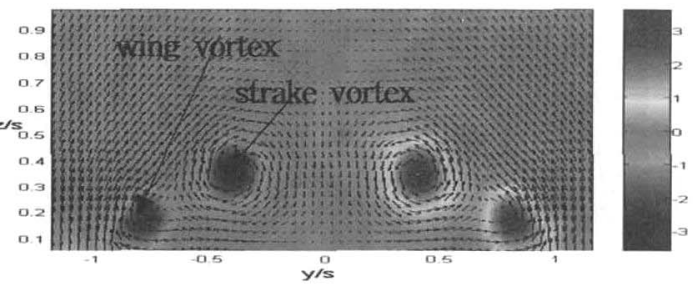

(b) $\mathrm{x} / \mathrm{c}=\mathbf{0 . 5 0}$

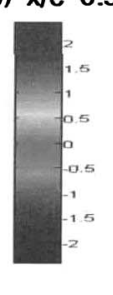

and streamwise vorticity $\left(\alpha=24^{\circ}, \delta=0^{\circ}\right)$ 
The surface pressure distribution is influenced by not only the strength of the vortices but also their locations relative to the wing surface. Even though, the relative strength of strake vortex at $\mathrm{x} / \mathrm{c}=0.3$ location was the strongest, it did not produce much an effect to the surface pressure distribution since its core location was far off from the wing surface, while the weaker wing vortex at $\mathrm{x} / \mathrm{c}=0.7$ which was located near the wing surface helped produce a sharp suction pressure peak as can be observed in Fig. 5 later.

Fig. 4 shows the effect of the strake incidence-angle on the vortex development and interaction for the double-delta wing model of the present study. It is observed that by the positive strake incidence-angle of $\delta=+15^{\circ}$ the strake vortex moved upward significantly from the wing-upper surface and it moved downward toward the wing-upper surface by the negative strake incidence-angle of $\delta=-15^{\circ}$. The pair of the strake vortices at $\delta=-15^{\circ}$ were positioned very close to the wing-upper surface as shown in Fig. 4b. At the $50 \%$ chord station, the wing vortices are observed to locate outboard and adjacent to the wing surface(Figs. $4 \mathrm{c}$ and d). The strengths of the strake vortices were decreased at $\delta= \pm 15$ degree, compared to the zero strake incidence-angle. The size and strength of the strake and wing vortices were comparable with each other for the case of $\delta=0^{\circ}$. The strake vortex was stronger than the wing vortex for the case of $\delta=+15^{\circ}$ and the wing vortex was stronger than the strake vortex for the case of $\delta=-15^{\circ}$.

The coiling and merging of the strake and wing vortices were pronounced at $\delta=-15^{\circ}$ and delayed at $\delta=+15^{\circ}$ compared to the case of $\delta=0^{\circ}$. For example, the strake and wing vortices of the $\delta=0^{\circ}$ case rotated about $90^{\circ}$ as the flow proceeds from $\mathrm{x} / \mathrm{c}=0.50$ to 0.70 , while those of the $\delta=$ $-15^{\circ}$ case merged into one vortex system as the flow proceeds from $\mathrm{x} / \mathrm{c}=0.50$ to 0.70 . It is summarized that the effect of a negative strake incidence-angle was the movement of the strake and wing vortices closer to the wing-upper surface and the enhanced coiling interaction between them. The effect of a positive strake incidence-angle was the movement of the strake vortex away from the wing-upper surface and the delayed coiling interaction between them. Also the strengths of the wing and strake vortices were reduced by the positive strake incidence-angle.

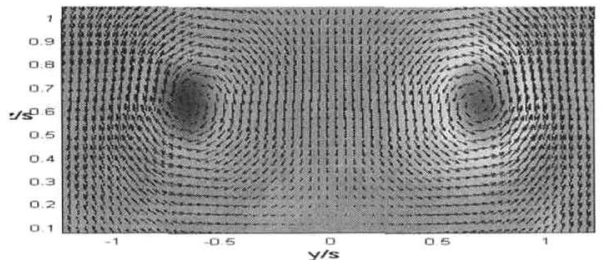

(a) $\delta=+15^{\circ}, x / c=0.30$

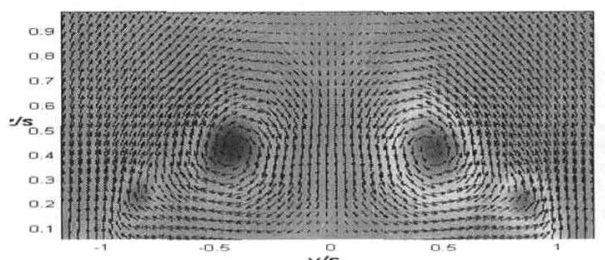

(c) $\delta=+15^{\circ}, \mathrm{x} / \mathrm{c}=0.50$

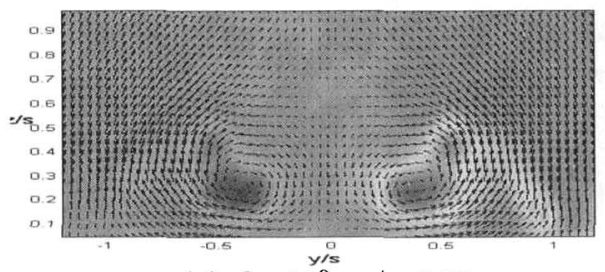

(e) $\delta=+15^{\mathrm{y} / \mathrm{s}}, \mathrm{x} / \mathrm{c}=0.70$
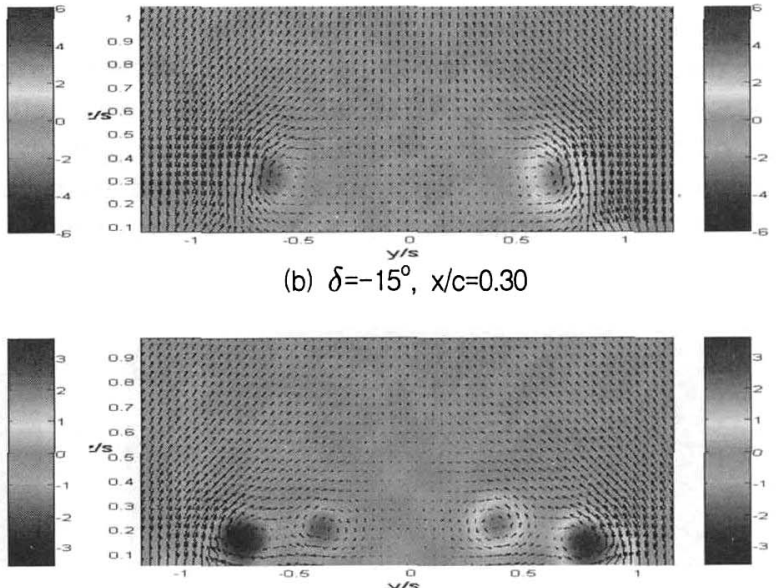

(d) $\delta=-15^{\circ}, x / c=0.50$
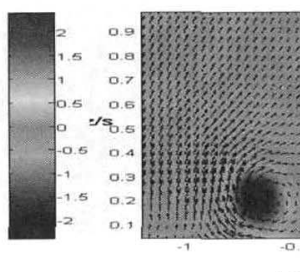

(f) $\delta=-15^{\circ}, x / c=0.70$

Fig. 4. Cross-flow velocity and streamwise vorticity at non-zero strake incidence-angle $\left(\alpha=24^{\circ}\right)$ 
This change of the relative vortex positions and the change of the strength of each vortex will be projected directly on the suction pressure distribution on the wing upper surface.

Fig. 5 compares the wing-upper surface pressure distributions for the change of the apex strake incidence-angles at the two representative angles of attack $24^{\circ}$ and $32^{\circ}$. Fig. 5 shows that the magnitude of the suction pressure on the wing-upper surface increases as the strake incidence angle increases to the negative direction, and it decreases as the strake incidence angle increases to the positive direction. Also the position of the suction peak moves outboard at the negative strake incidence angle, and it moves inboard at the positive strake incidence angle. It seems that the effect of the stake incidence angle is consistent in changing the magnitude of the suction pressure on the wing-upper surface and its peak position both for the two representative angles of attack, which is a desirable characteristic in point of using the apex strake as the vehicle control device.

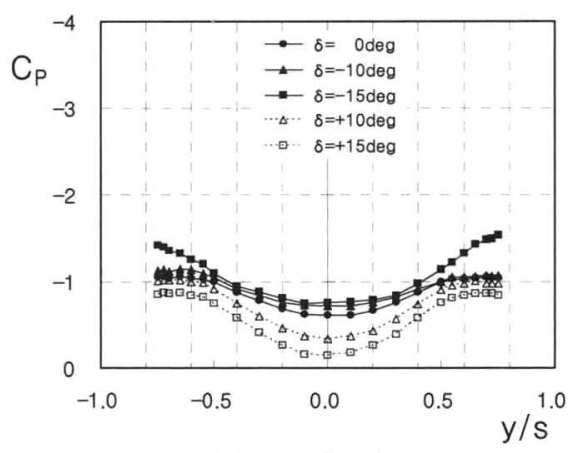

(a) $a=24^{\circ}, x / c=0.3$

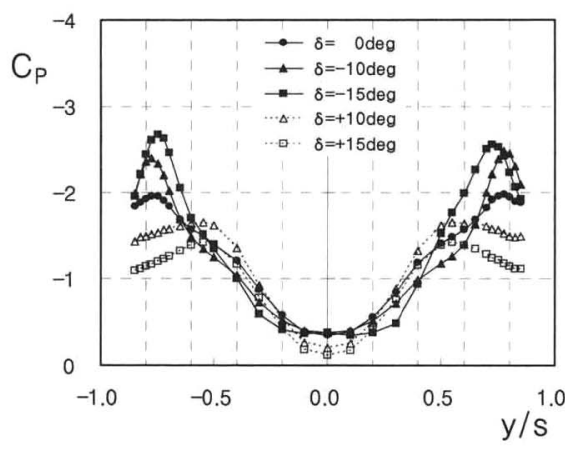

(c) $a=24^{\circ}, x / c=0.5$

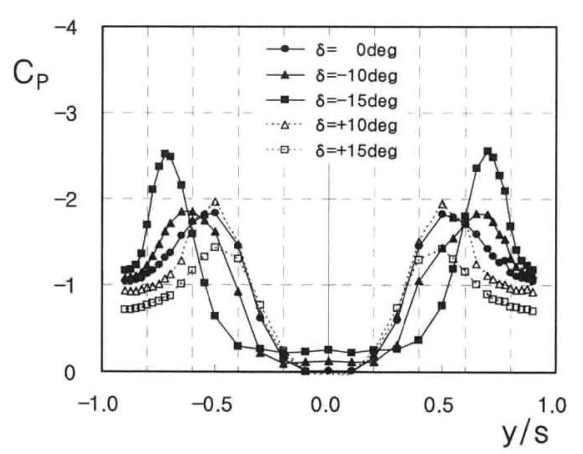

(e) $a=24^{0}, x / c=0.7$

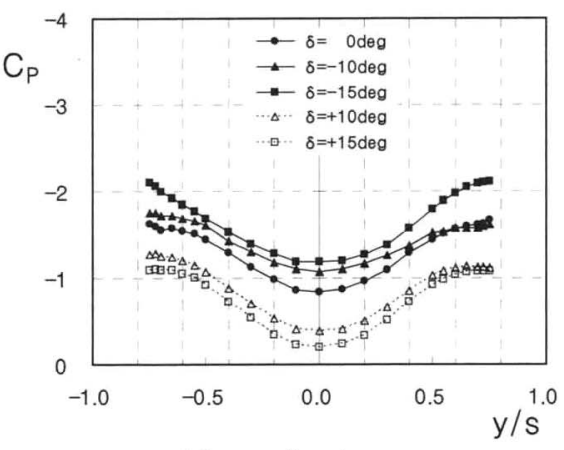

(b) $a=32^{\circ}, x / c=0.3$

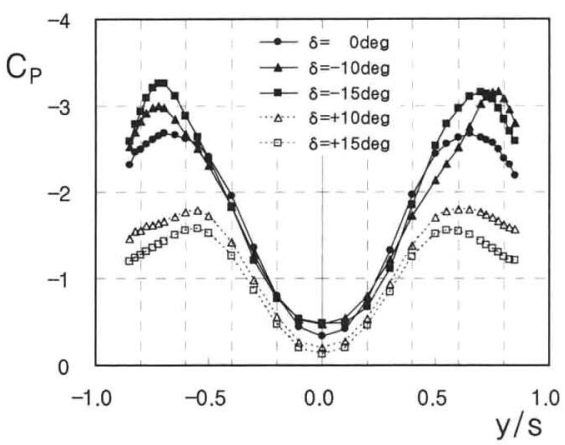

(d) $a=32^{\circ}, x / c=0.5$

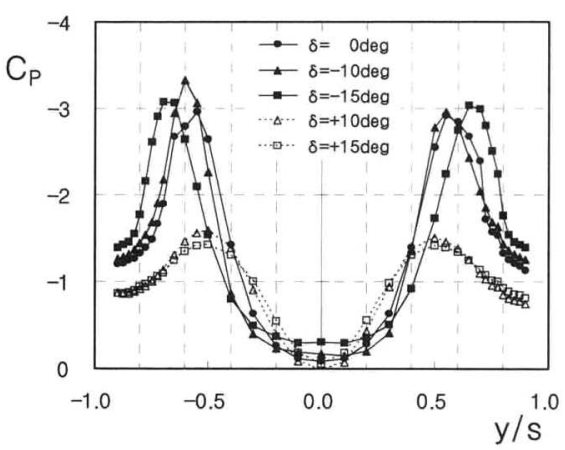

(f) $a=32^{\circ}, x / c=0.7$

Fig. 5. Effect of strake incidence-angle on the wing-upper surface pressure distribution at the two representative angles of attack 
The increase of the magnitude of the suction pressure on the wing-upper surface of delta wings at high angle of attack occurs when the strength of the vortices is increased and/or the vortex core is located near the wing surface. A sharp suction pressure peak is an indication of the concentrated vortex or the vortex pairs vertically aligned to the wing surface[10, 14]. Since the angle of attack is defined as the angle between the main wing surface and the free stream velocity in the present study, the positive strake incidence-angle increases the local angle of attack of the strake and the negative strake incidence-angle decreases it. Therefore, the increase of the magnitude of the suction pressure at the negative strake incidence-angle as shown in Fig. 5 is due to the fact that the wing and strake vortices located close to the wing-upper surface, not due to the increase of the vortex strength. The PIV results of Fig. 4 showed that the strengths of the wing and strake vortices for the case of $\delta=-15^{\circ}$ are weaker than those for the case of $\delta=0^{\circ}$.

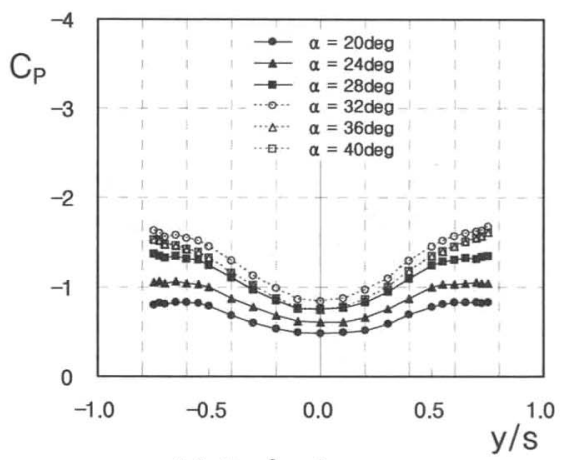

(a) $\delta=0^{\circ}, x / c=0.3$

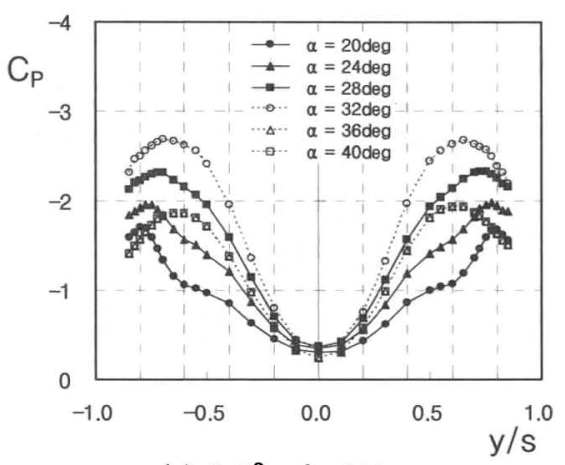

(c) $\delta=0^{\circ}, x / c=0.5$

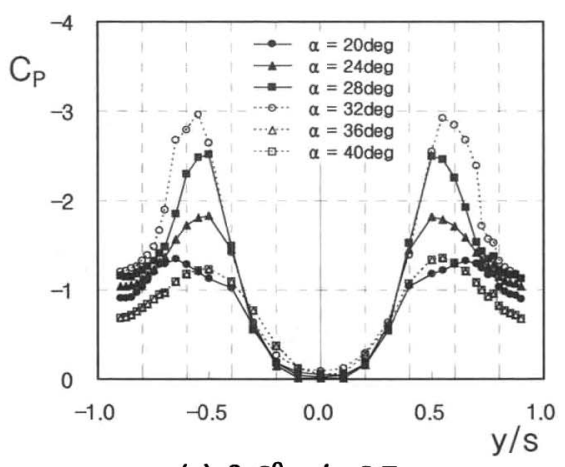

(e) $\delta=0^{\circ}, x / c=0.7$

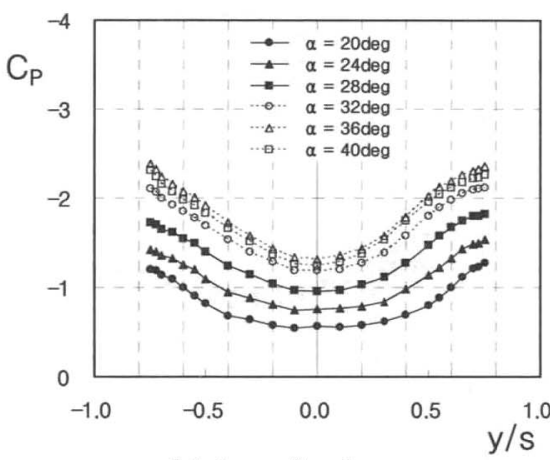

(b) $\delta=-15^{\circ}, x / c=0.3$

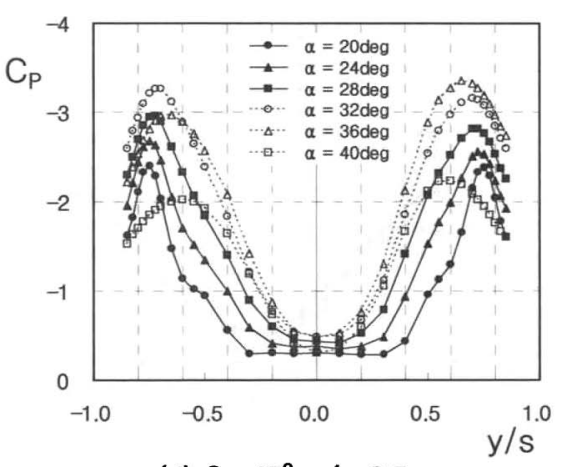

(d) $\delta=-15^{\circ}, x / c=0.5$

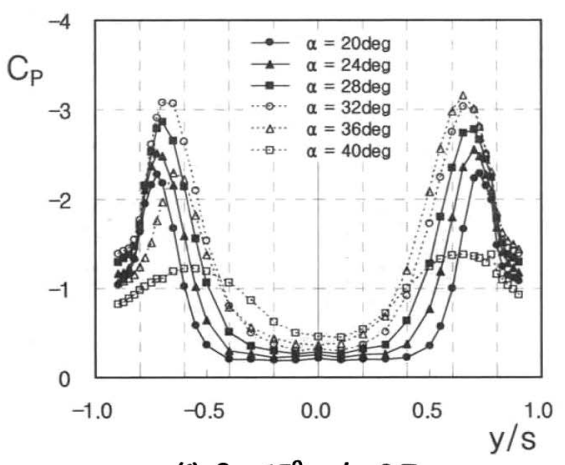

(f) $\delta=-15^{\circ}, x / c=0.7$

Fig. 6. Comparison of wing-upper surface pressure distributions at strake incidence-angles, $0^{\circ}$ and $-15^{\circ}$ 
Fig. 6 illustrates the effect of strake incidence-angle at various angles of attack on the wing-upper surface distributions. For both cases of $\delta=0^{\circ}$ and $-15^{\circ}$, the magnitudes of pressure distribution generally increased as the angle of attack increased up to $\alpha=32^{\circ}$, and the suction pressure peaks collapsed at $\alpha=36^{\circ}$ and beyond, indicating vortex breakdown. However, the $\delta=-15^{\circ}$ case produced much higher and more concentrated suction pressure peaks at outboard region of the wing. In addition, the pressure distribution of $\delta=-15^{\circ}$ case did not entirely collapsed and still generated some lift at $\alpha=36^{\circ}$ and beyond. The suction peaks at outboard region were produced by the wing vortices remained near the wing surface as seen in Fig 5. Through these observations, it can be concluded that the negative strake incidence-angle has effects of weakening the strake vortices and lowering their positions near the wing surface. This phenomenon causes the wing vortex dominated vortex merging process which, in turn, allowing the wing vortex to remain near the wing surface with the concentrated vortices formation; therefore, the lowering the incidence angle can delay the vortex breakdown and retain the lift force at higher angles of attack.

Klute et al.[3] reported that apex flap could delay vortex breakdown by an angle of $8^{\circ}$ beyond the steady-flow breakdown angle of attack with their $75^{\circ}$-sweep single delta wing model. The apex flap of Klute et al.'s study was obtained by drooping the apex portion at the $40 \%$ chord station from the apex of their single-delta wing. The peaked suction pressure distributions with large magnitude even at the $70 \%$ chord station for $\delta=-15^{\circ}$ and $a=32^{\circ}$ as shown in Fig. $6 \mathrm{f}$ imply that the vortex system at the negative strake incidence-angle is stabilized and concentrated for the delta-wing model of the present study, which supports the conclusion of Klute et al.'s study. Sohn et al.[15] examined the effect of the micro leading edge flaps on the vortex characteristics of a double-delta wing with apex strake, which showed that the micro leading edge flaps could alter the vortex flow pattern and the wing-surface pressure distribution especially in spanwise direction. Therefore, the variable apex strake of the present study can provide another flow control mechanism of double-delta wing vortex in addition to the micro leading edge flaps of reference 15.

\section{Conclusion}

The present study examined the vortex flow characteristics of a double-delta wing with variable apex strake through the wing-surface pressure measurement and the particle image velocimetry(PIV) measurement of the wing-leeward flow region. The suction pressure on the wing-upper surface increased in magnitude as the strake incidence angle increased to the negative direction, and decreased as the strake incidence angle increased to the positive direction. Also the position of the suction peak moved outboard for the negative strake angles. PIV measurements made it possible to analyze the flow structure pattern which helped explain the physical characteristics of the pressure distribution variation with respect to the change in strake incidence angles.

The present study revealed that the incidence-angle change of the apex strake could greatly alter the vortex flow pattern around the double-delta wing and the wing-surface pressure distribution, which suggested that the apex strake could be used as an effective device for the active flow control of delta- ${ }^{-}$ing vortex flow

\section{Acknowledgement}

This work was supported from the Basic Research Program of the Korea Science and Engineering Foundation (Grant Number R01-2003-10744-0)

\section{References}

1. Gursul, I., Yang, H., and Deng, Q., "Control of Vortex Breakdown with Leading-Edge Devices," AIAA Paper 95-0676, January 1995. 
2. Rao, D. M., and Buter, A., 1983, "Experimental and Computational Studies of a Delta Wing Apex-Flap", AIAA Paper 83-1815.

3. Klute, S. M., Rediniotis, O. K., and Telionis, D. P., 1996, "Flow Control over a Maneuvering Delta Wing at High Angles of Attack", AIAA Journal, Vol. 34, No. 4, pp. 662-668.

4. Zhan, J. and Wang, J., "Experimental Study on Gurney and Apex Flap on a Delta Wing", Journal of Aircraft, Vol. 41, No. 6, 2004, pp. 1379-1383.

5. Lee, G., Shih., C, Tai, Y., Tsao, T., Liu, C., Huang, A., and Ho, C.-M., 2000, "Robust Vortex Control of a Delta Wing by Distributed Microelectromechanical-Systems Actuator", Journal of Aircraft, Vol. 37, No. 4, pp. 697-706.

6. Folk. C. and Ho, C.-M., , 2000, "Micro-Actuators for Control of Delta Wing with Sharp Leading Edge", AIAA Paper 2001-0121.

7. Barberis, D., Molton, P., Renac, F., and Mitchell, A. M., 2004, "Vortex Control on Delta Wings", AIAA Paper 2004-2620.

8. Rinoie, K., 2000, "Experiments on a 60-Degree Delta Wing with Rounded Leading-Edge Vortex Flaps", Journal of Aircraft, Vol. 37, No. 1, pp. 37-43.

9. Marchman III J. F., and Grantz, A. C., 1982, "Trailing Edge Flap Influences on Leading Edge Vortex Flap Aerodynamics", AIAA Paper 82-0128.

10. Sohn, M. W., and Chung, H. S., 2006, "Effects of Strake Planform on the Vortex Flow of a Double-Delta Wing", Journal of the Korean Society for Aeronautical and Space Sciences, Vol. 34, No. 8, pp. 16-23.

11. AIAA Standard, "Assessment of Experimental Uncertainty with Application to Wind Tunnel Testing", AIAA S-071A-1999.

12. Lehr, A. and Bölics, A., 2000, "Application of a Particle Image Velocimetry(PIV) System to the Periodic Unsteady Flow Around an Isolated Compressor Blade", $15^{\text {th }} \mathrm{Bi}$-Annual Symposium on Measurement Techniques in Transonic and Supersonic Flow in Cascades and Turbomachines, University of Florence.

13. Lim, H. C. and Lee, S. J., 2002, "Flow Control of Circular Cylinders with Longitudinal Grooved Surfaces", Journal of Aircraft, Vol. 40, No. 10, pp. 2027-2036.

14. Sohn, M. H., Chung, H. S., and Chang, J. W., 2006, "Effects of Strake Incidence-Angle on the Vortex Flow of a Double-Delta Wing", Journal of the Korean Society for Aeronautical and Space Sciences, Vol. 34, No. 11, pp. 7- 15.

15. Sohn, M. H., Chung, H. S., and Cho, D. H., 2006, "Control of Delta-Wing Vortex by Micro-Fin-Type Leading-Edge Flap, KSAS International Journal, Vol. 7, No. 2, pp. 128-136. 